\title{
What is Xenosophia? Philosophical Contributions to Prejudice Research
}

\author{
Heinz Streib \\ (Chapter 1 in: H. Streib, C. Klein (eds.), Xenosophia and \\ Religion. Biographical and Statistical Paths for a Culture of \\ Welcome, pp. 3-12, https://doi.org/10.1007/978-3-319-74564-0_1)
}

This book is about the development and sustainability of a culture of welcome in times of increasing prejudice against immigrants and xenophobia toward refugees. To ground this discussion empirically, the book presents analyses of the qualitative and quantitative data from our Bielefeld Study on Xenosophia and Religion in Germany - thereby identifying biographical paths and statistical paths toward xenophobia and xenosophia.

Empirical research, however, needs to explicate the conceptual framework on which it is based. And already the generally synonymous used concepts of prejudice and xenophobia may require some explication. But certainly our key concept, xenosophia, is not taken-for-granted, but new in research on prejudice and in the scientific study of religion, and may be rather unfamiliar to many readers. In this first chapter, therefore, we intend to answer four questions:

(a) we explain why there is need for complementing the preoccupation for prejudice and xenophobia (the "pathogenic" model) in research and public discussion with a perspective on the positive developments (a "salutogenic" model);

(b) we explain why we chose the concept of xenosophia to signify the opposite to xenophobia and prejudice, and why we prefer xenosophia;

(c) we give details about how xenosophia is grounded in philosophical thought; thereby we will present the lines of argumentation in Waldenfels' and Nakamura's works about the alien;

(d) we explain how xenosophia has been operationalized for our empirical research on prejudice.

\section{Prejudice and Religion}

One of the most influential contributions to research on prejudice and on the relation between religion and prejudice is presented in the work of Allport $(1954,1966)$. And, with Allport, we understand 'prejudice' as an "avertive or hostile attitude toward a person who belongs to a group, simply because he belongs to that group" (p. 7) and as "antipathy based upon a faulty and inflexible generalization" (p. 9), which, when acted out, may escalate from "antilocution" to "avoidance" and to "discrimination," and finally lead to "physical attack" and "extermination" (p. 14-15). When we associate 'xenophobia' to 'prejudice,' we intend to (a) focus the prejudice on (groups of) strangers such as immigrants and refugees, and (b) to underscore the emotional aspect that Allport's "antipathy" refers to. 
What has prejudice to do with religion? As well-known and frequently cited, Allport claimed that religion can both "make" and "unmake" prejudice. But Allport (1954, p. 456) went further and introduced a differential perspective: he claimed that the promotion of prejudice is connected with the religion "of an ethnocentric order" and the prevention of prejudice is connected with the religion "of a universalistic order." It is important to take this differential perspective into account, because the "religion of a universalistic order" that may contribute to the "unmaking" of prejudice could be an important contribution to profiling a "salutogenic" model.

\section{The "Pathogenic" Model}

Since Allport we have seen an immense body of research on religion and prejudice, which primarily documents that religion tends to be associated with prejudice against people, who are regarded different, other or alien with respect to their ethnic background, color of their skin, their sexual orientation or their religious beliefs and practices (see Hood, Hill, \& Spilka, 2009, for a review). The "pathogenic" effect of religion is well documented (see also Chap. " 2 " in this book). Thereby, in major lines of research, "ethnocentrism" emerged as a popular construct and was explicitly included in the names of measures (e.g. Adorno, Frenkel-Brunswik, Levinson, \& Sanford, 1950; Altemeyer 1996, 2003), while "universalism" is rather absent. Thus we have seen a profiling of the effects of the "ethnocentric" type of religion.

For example, Altemeyer and Hunsberger (1992; Hunsberger, Owusu, \& Duck, 1999; Altemeyer, 2003; see Hunsberger \& Jackson, 2005; Altemeyer \& Hunsberger, 2005; for reviews) studied religious fundamentalism and right-wing-authoritarianism and their relation with negative attitudes toward women, blacks, Jews, or homosexuals. Their scales for religious fundamentalism (Altemeyer \& Hunsberger, 1992, 2004) and right-wing authoritarianism (Altemeyer, 1996, 2006) are widely used in research on prejudice. The Right-wing Authoritarianism Scale has three subscales: submission ("a high degree of submission to the established, legitimate authorities in their society," Altemeyer, 2006, p. 9), aggression ("high levels of aggression in [5] the name of their authorities") and conventionalism. For religious fundamentalism and how it is causing prejudices, Altemeyer and Hunsberger (1992, 2005) identified at least four mechanisms: first, that religious fundamentalism is characterized by moral dualism, a simplified worldview distinguishing sharply between good and bad; the other three mechanisms are the need for social strength of one's own ideol- ogy and group, the belief that one's own faith is exclusively true, and a refusal of pluralism.

We can identify in this detailed characterization of the fundamentalist and authoritarian mind set several religious schemata, ${ }^{1}$ one of which we have operationalized for empirical research and included in our Religious Schema Scale (RSS, Streib, Hood, \& Klein, 2010): the RSS subscale truth of texts and teachings (ttt). Conceptually, as religious-cognitive schema, the $t t t$ schema clearly corresponds to the conventionalism of the Right-wing Authoritarianism Scale and to the characteristic of absolute truth of one's own religion in the Religious Fundamentalism Scale. An empirical confirmation of these correspondences are, as estimated in the data of our Bielefeld-based Cross-cultural Study on Deconversion (Streib, Hood, Keller, Csöff, \& Silver, 2009, p. 73), high correlations of the $t t t$ subscale with religious fundamentalism (Altemeyer \& Hunsberger, 1992) of $r_{U S A}=.80$ and $r_{B R D}=.81$ 
and with right-wing authoritarianism (Altemeyer, 1996) of $r_{U S A}=.68$ and $r_{B R D}=.72$.

In the research on religion and prejudice, we observe a tendency to focus on the negative, pathogenic side, on how the religion "of an ethnocentric order" "makes" prejudice. Taken together, in this research tradition, we have a characterization of religious schemata that may help us explain the development of prejudice and xenophobia. Religious fundamentalism, conventionalism, and authoritarian submission and aggression contribute to the development of a prejudiced mindset. This clearly profiles the ethnocentric habitus, including the "ethnocentric" type of religionwhere "ethnocentric" means that one's own group, tribe, religious group or political establishment is the exclusive center of interpretation authority, moral judgment and legitimization of aggression against out-groups. In the framework of the "pathogenic" model, i.e., under the dominance of fundamentalism and authoritarianism, religion appears to have little chance for "unmaking" prejudice. [6]

\section{The "Salutogenic" Perspective}

Complementing the "pathogenic" model with a "salutogenic" view is an important contribution to the psychology of religion, because we need to find ways of how people and societies can escape from the vicious circle of prejudice, xenophobia and violence. Thus, the conceptual clarification and operationalization of schemata different from the "pathogenic" schemata is an important task. Research could attend to the other side of religion: the potential of religion for conflict-solving, peace-making and prejudice reduction.

Peace is more than the absence of war. Peace needs to be described positively as the condition for optimal human development, including conditions such as food and shelter, education, and freedom of religion. Likewise, for conceptualizing optimal inter-cultural and inter-religious relations, we need a positive vision, that suggests more than the absence of prejudice, hate and violence. Xenosophia, this our thesis, presents us with the semantic option of a positive antonym for prejudice and xenophobia.

We may indicate the direction in which the vector of the "salutogenic" model is aiming. With reference again to Allport, the "salutogenic" perspective includes the view that the prevention, the "unmaking" of prejudice is connected with the religion "of a universalistic order." What "universalism" might signify is connected with its polar opposition: "ethnocentrism." This polarity can be interpreted in a helpful way in the framework of values according to Schwartz $(1992,2003)$. The polarity between "ethnocentrism" and "universalism" reflects the polarity between self-enhancement and self-transcendence - the y-axis in the value space (see Chap. 9 for more details). "Self-transcendence," which is composed in the value space by the values of benevolence and universalism, means not holding on to one's own supposedly dominant worldview and value system, but reaching out to, or being concerned with "other" beings and possibly relating to humanity and/or the universe. It is probably not mistaken to draw a line also to the construct of Identification

\footnotetext{
${ }^{1}$ For the concept of 'schema' as applied in the Religious Schema Scale, see Streib, Hood and Klein (2010, p. 153-154). Another schema that can be identified in Altemeyer and Hunsberger's research is particular interesting: the schema of exorcism (cf. Schäfer 2015, for the definition and characterization of the exorcism schema for the identity and praxis in the neo-Pentecostal movement of Guatemala), which clearly corresponds to the subscale aggression in the Right-Wing Authoritarianism Scale.
} 
with All Humanity and the IWAH Scale (McFarland, Webb, \& Brown, 2012; McFarland, Brown, \& Webb, 2013), which attends to the differential extension of in-group identification to a universal perspective - but may also, with a second factor, tap into benevolence and prosocial attitudes (Reysen \& Hackett, 2015). And even though McFarland's IWAH Scale does not assess specifically xenological attitudes, the identification with all of humanity may be an effective predictor for prejudice reduction.

Despite such conceptual and empirical commencements, there is no broad and well-established research tradition about reducing prejudice and moderating xenophobia. Especially when we search for designs including a perspective on religion, we have nothing comparable with the research on social pathologies mentioned above. From their evaluation of almost a thousand reports on prejudice reduction interventions, Paluck and Green (2009, p. 360) conclude that "psychologists are a long way from demonstrating the most effective ways to reduce prejudice," because [7] existing studies are lacking "internal and external validity." As recently reported by Paluck (2016), there are only ca. 11\% real-world field studies, while the majority of ca. $60 \%$ reports are about nonexperimental intervention, which, despite the abun- dance of creative ideas, nevertheless provide no reliable answers to the question of what reduces prejudice in real-world settings (Paluck \& Green, 2009, p. 360). And, interestingly enough, the huge Princeton Prejudice and Conflict Reduction Database, which Paluck and Green used for their review, does not include one study demonstrating the effects of religiosity or spirituality on prejudice reduction. Therefore, it is no surprise that Doehring (2013), in her chapter on how religion and spirituality contribute to or counteract prejudice and discrimination, could not pres- ent much evidence about the specific effects of religion or spirituality, but thought- fully suggests "implementing religious or spiritual values" in extant research-based intervention proposals such as the reduction of automatic activation prejudice, the role of positive guilt feeling about a person's own prejudices, or intervention with positive role models.

We may conclude that the "salutogenic" model of the reduction of prejudice and the prevention of xenophobia is not yet based on a solid body of empirical evidence. The conceptual perspectives and research instruments are not as well established as in research on prejudice and xenophobia.

Nevertheless, we may begin with looking for the hints and emerging structures that may contribute to the conceptualization and operationalization of developments to "unmake" prejudice. Previous studies on prejudice reduction could make a considerable contribution here. The following selection of recent experimental studies (that all were published after Paluck and Green's extensive review study) may help us suggest at least a preliminary answer to the question "what works in prejudice reduction," and thus indicate contours of a "solutogenic" perspective.

- Tadmor and colleagues (2012) tested the reduction of intergroup bias through what they call "epistemic unfreezing." For multicultural exposure and experimental exposure to multicultural experience, their series of experimental studies demonstrated a reduction of stereotypes, symbolic racism and discrimination, and a reduction of the need for cognitive closure.

- Prejudice reduction can be induced by counter-stereotypes and by creative cognition, as demonstrated in the study of Goclowska and Crisp (2013).

- Also, perspective-taking manipulation, e.g., by the task of writing a short narrative about an unknown (culturally "other") target person, has effects on auto- 
matic intergroup evaluations, as Todd and Burgmer (2013) have tested in their series of experiments. These studies demonstrate how perspective-taking could have a prejudice reducing effect.

- Er-rafiy and Brauer $(2010,2011,2012)$ studied the effects of perceived variability on prejudice reduction. By interventions such as showing a documentary or showing a poster that presents differences among the target group (in this case: Arabs), the experiments demonstrated prejudice reducing effects for the target groups compared to the control groups.

[8] Reading across the research designs of these studies, we may identify patterns of prejudice reduction mechanisms, which can be summarized as follows:

a. Experiences of multicultural "otherness" such as past real-world multicultural exposure, or the eliciting or recalling of experiences of multicultural "otherness," for example in an essay writing experiment, leads to reduction of prejudice and to a reduced need for cognitive closure.

b. The invitation to the cognitive engagement (e.g., in essay writing) with a "strange" person, who is a person from another culture, is an invitation to perspective-taking - and such perspective-taking has prejudice reducing effects.

c. The encounter with an amazing or perplexing difference and variety in the "strange," e.g., in the form of perceived variability in a group of "strangers" who eventually are the object of prejudice and discrimination, reduces prejudice.

d. The encounter with creative linguistic alienations, such as counter-stereotypes, reduces prejudice.

The common pattern in these four "mechanisms" is the assumption that prejudice reduction - the "unmaking" of prejudice-emerges from the encounter with difference, with otherness, with strangeness. And the studies document that this "works," thus giving answers to the question "what works in prejudice reduction." These four purposefully selected pieces of research may help us delineate the contours of the "salutogenic" perspective on the reduction of xenophobia and prejudice. Definitely, this line of research has to eventually go beyond class-room research, include real-world field experiments and a more representative selection of the adult population, as Paluck (2016) rightly and repeatedly suggests.

To be clear, studies such as the ones presented above are a beginning and not much more than that. There should be more coherence to constitute a "salutogenic" line of research. These studies may indicate a promising beginning suggesting that we may wish to include a still other set of predictors than the need for cognitive closure or the need for cognition (that nevertheless reveal as effective predictors, see e.g. Van Hiel, Pandelaere, \& Duriez, 2004; Brandt \& Reyna, 2010; Dhont, Roets, \& Van Hiel, 2013). These experimental interventions operate with experiences of otherness/strangeness, with a difference in perspective and the irritations that come with that. Thus, research on prejudice reduction is well advised to consider constructs such as tolerance of complexity - and eventually xenosophia, since xenosophia operates with a tolerance for the irritation, resistance and, the demand that it is presented by the experience of strangeness, as will be discussed below. 


\section{Why 'Xenosophia'? And why Is it Superior to 'Tolerance'?}

What is the opposite of prejudice and xenophobia? It is illuminating that, for signifying the positive developments, mostly negations are used such as "prevention," "reduction," "counteracting" or "overcoming." Obviously there is some uncertainty regarding positive antonyms.

[9] There are, of course, a row of candidates for antonyms to xenophobia and preju- dice, for example: 'tolerance,' 'fairness,' 'open-mindedness,' 'acceptance,' 'respect,' 'generosity,' 'xenophilia,' 'identification with all of humanity' - and, not to forget, Allport's association to 'universalism.' In this context of antonyms, we suggest to also consider 'xenosophia.' Each of these potential antonyms indicates a vision for an individual and for a society without prejudice and xenophobia. And these visions differ to some extent, when one or the other antonym is highlighted.

Instead of discussing the antonym candidates one by one, I will start the discussion by focusing on two concepts, namely 'tolerance' and 'xenosophia.' This selection is, of course, inspired by the structure and profile of the subscales that we have included in the Religious Schema Scale (Streib et al., 2010), which in turn correspond to a selection of religious styles as presented in Fowler's (1981) model of faith development and in Streib's (2001) model of religious styles. Thus, the discussion will include a focus on the two schemata: (a) on the schema of fairness, tolerance and rational choice (ftr), which is a characteristic of Style/Stage Four of "individuative-reflective faith" (Fowler) / the "individuative-systemic style" (Streib), and (b) of the schema of xenosophia/inter-religious dialog (xenos), which is a characteristic of Style/Stage Five of "conjunctive faith" (Fowler) / the "dialogic religious style" (Streib).

'Tolerance' qualifies for discussion not only because this concept is the basis of the ftr subscale, but also because 'tolerance' enjoys the most frequent use as an antonym for prejudice in the literature. But words can have a variety of meanings, and 'tolerance' is no exception. In the ftr subscale name, 'tolerance' is embedded between 'fairness' and 'rational choice.' Such interpretation with the help of explicit associations, I claim, is necessary to state more precisely how to understand the ftr schema.

Forst (2013) suggests distinguishing four conceptions of tolerance: (1) the "permission conception," (2) the "coexistence conception," (3) the "respect conception" and (4) the "esteem conception." "Tolerance' in the associative context with "fairness' and 'rationality,' as in ftr, primarily corresponds to the "respect conception" (Forst's third conception), which is grounded in mutual respect despite the recognition of profound ethical and cultural differences. But the meaning of 'tolerance' in the ftr schema may reflect also features of the "esteem conception," which is the forth and "ethically thickest" (p. 32) in Forst's typology. Here, 'tolerance' means

\footnotetext{
"not only respecting the members of other cultural or religious communities as legal and political equals but also esteeming their convictions and practices as ethically valuable" (Forst, 2013, p. 31).
}

In any case, the fair and rational and thus tolerant relation to the "other" in the ftr schema is going beyond Forst's "permission conception" (e.g., the toleration of minorities, as long as they are satisfied with the rights granted by the established power) and the "coexistence conception" (e.g. the mutual renunciation of violence), which are ethically "thinner," because they are either based on an asymmetric imbalance of power, or characterized by mutual disinterest. In contrast, the association 
with respect and esteem and with fairness and rationality qualifies 'tolerance' as favorable antonym for prejudice and xenophobia. 'Tolerance' in this understanding [10] transports the vision of communities and societies, in which mutual respect - and eventually positive esteem - for the convictions and practices of the "other" outdoes prejudice and xenophobia. This opens a "salutogenic" view.

We can, however, still imagine a comparative. And this comparative is indicated by the schema of xenosophia. Nevertheless, the "esteem conception" of tolerance foreshadows and prepares for xenosophia. Without fair and rational tolerance, xenosophia cannot develop. There is a gradual transition and overlap between $\mathrm{ftr}$ and xenos. To explain the comparative, which is presented by xenosophia, we need to converse with the philosophy of strangeness/alienness. And here Waldenfels' philosophy of alien is convincing.

As a kind of intermediary step, I first however wish to relate my line of argument to the discussion on tolerance. I briefly discuss and explain, where I see the potentials for the comparative and where I see possible shortcomings of 'tolerance.' Thereby I first want to direct attention to the developmental modelling of religion, faith and worldviews. Fowler has seen the need to expand the hierarchical sequence of stages of faith beyond his Stage Four of individuative-reflective faith to Stages Five and Six of "conjunctive faith" and "universalizing faith." Leaving aside the question of the "logic of development" that is supposed to explain the dynamics that stimulate stage transition, I regard it as an ingenious idea to expand the sequence of stages or styles beyond individuative reflection. Fowler identified as one of the possible shortcomings of Stage Four to be

"an excessive confidence in the conscious mind and in critical thought and a kind of second narcissism in which the now clearly bounded, reflective self overassimilates "reality" and the perspectives of others into its own world view" (Fowler, 1981, p. 182-183).

With reference to the difference between accommodation and assimilation, as assumed in the developmental theory in the tradition of Piaget, Fowler's critique is directed toward the dominance of one's own world view and thus the mere assimilation of the "other," while questions or challenges toward their own system of categories are suppressed. What is missing, is the inter-action between the partners in communication and the specification of the eventually beneficial outcomes for both partners in inter-action. While the tolerant relation may lead to and include respect and eventually esteem for the other's world view and the other's cultural and religious practices, it leaves the category system of the observer unchanged.

This is different in the concept of xenosophia. Here, the basic assumption is that the "own" inter-acts with the "other" or "strange" to the effect that the "own" is challenged and receives inspiration to creatively change and develop new perspectives. The list of mechanisms that were implemented in the studies on prejudice reduction mentioned above may open a perspective on xenosophia. Despite the difficulties to clearly measure such outcomes, the assumptions are that perspectivechange, counter-stereotypes or recognition of differences in the other may lead to prejudice reduction - and to the emergence of something new.

Using 'xenosophia' in this way and assuming that the individual, from the interaction with the other/the strange receives challenges for re-evaluating his or her own world view, which eventually leads to creativity and wisdom, should be based 
[11] on convincing argumentation. Therefore, it is suggested that we more deeply enter into philosophical reflection about the relation between own and other, between the own and the strange/the alien.

\section{Philosophical Perspectives on the Alien and the Concept of Xenosophia}

While we are probably the first to introduce the term 'xenosophia' in empirical research and include it in the name of a scale, we are not the first to use the word. We have been inspired by Nakamura's (2000) book with the title Xenosophie, in which he presents philosophical reflections on xenographia, xenosophia and an outlook on xenology. As in the subtitle, Nakamura's book presents "building blocks for a theory of alienness."

Nakamura develops his perspective on xenosophia in a critical dialog with Husserl's and Waldenfels' phenomenological-philosophical thought. Thereby, Nakamura shares basic assumptions especially with Waldenfels. Therefore, we begin with Waldenfels' philosophy of the alien, proceed with Nakamura's advancement and precision, and conclude with our own conceptualization of xenosophia.

\section{Waldenfels'Phenomenology of the Alien}

Waldenfels (1990, 1997a, 1997b, 1999, 2007, 2011)3 presents a seminal perspective on the alien, which, this should be stated clearly from the beginning, does not discuss the alien merely in respect to global migration and growing multi-cultural plurality, but as part of a wider philosophical-phenomenological perspective. As Waldenfels explains:

"The alien is more than the mere symptom of a growing multiculturalism on the background of a globalization process. Phenomenologists could argue that the experience of the alien is one of the basic issues of phenomenological thought, and this being the case for a long time..." (Waldenfels, 2003, p. 23).

The perspective on the alien is embedded in a new kind of phenomenology, and Waldenfels identifies himself as phenomenologist, but as a phenomenologist of a

\footnotetext{
${ }^{2}$ A note about terminology: Since Waldenfels uses 'the alien' and 'alienness' in his English publications, I want to be consistent with his terminology. In my own text, I nevertheless prefer to talk about 'strangeness' and 'the Strange,' in order to avoid or minimize the misunderstanding of 'the alien' as person. Instead it should be stated clearly that 'the alien' is the translation of 'das Fremde,' which in the German language is a generalized neuter.

${ }^{3}$ Almost all of Waldenfels' texts are in German language and we have only very few translations into English. The texts (Waldenfels, 2003, 2011) from which quotes in this chapter are taken are among the few English publications by Waldenfels.
} 
[12] special kind: The experience of the other "requires a new sort of responsive phenomenology," which "goes beyond the traditional form of intentional phenomenology just as it leaves behind every sort of hermeneutics" (Waldenfels, 2003, p. 23). Waldenfels explains that "(r)esponding means more than intending or understanding." Consistent with his propagation of the new kind of responsive phenomenology, Waldenfels intends to develop a

\begin{abstract}
"special logic of response that differs considerably from the logic of intentional acts, from the logic of comprehension or from the logic of communicative action. It leads to a proper form of rationality, namely a rationality which arises from responsivity itself." (Waldenfels, 2003, p. 32).
\end{abstract}

Such response is a creative act:

"The response is creative as a response, i.e., as a form of saying and doing which begins elsewhere, yet without being grounded in a given sense of in existing rules. Creative responses are responses which are not pre-given, neither in the realm of things nor in the realm of words. Thus responding runs over a small ridge which separates bondage (Hörigkeit) from arbitrariness (Beliebgkeit).” (Waldenfels, 2003, p. 35).

Responsive phenomenology leads to a different understanding of the relation between subject and world; it also implies a radical understanding of the alien:

"(T)here is no world in which we will ever be completely at home, and there is no subject which will ever be the master of its own house. This kind of twilight of the idols confronts us with a radical sort of alien that precedes all efforts of appropriation - like the Other's gaze which meets us before we become aware of it." (Waldenfels, 2003, p. 24).

This reflects one of the characteristics that Waldenfels notes for the alien: the characteristic of atopia. The alien has no place. Waldenfels explains:

"(T)he alien's place is a peculiar place. It resists any attempt to insert it into a local grid which would be accessible to everyone; it can only be reached crossing a certain threshold. ... (A)bsence, distance or inaccessibility is inherent to the alienness or otherness as such. In this regard the alienness resembles the past which cannot be grasped anywhere else than in its after effects or by memory. The alien does not simply dwell elsewhere, it appears itself as an elsewhere, as a form of atopia, just as in the line of Plato who describes Socrates as atopos, as somebody strange, as placeless." (Waldenfels, 2003, p. 26).

What are the effects of the encounter with the alien? Waldenfels $(2011$, p. 84) claims that the alien "takes us outside ourselves and lets us transcend the boundaries of the specific order." Concluding his Phenomenology of the Alien, Waldenfels says:

"As a phenomenologist, I propagate a specific kind of epoché that instigates a suspension of assumptions that are taken for granted, a departure from the familiar, a stepping-back in front of the alien." (Waldenfels, 2011, p. 84).

The alien, Waldenfels claims, offers a surplus and creates new insights. He says:

"The alien... brings itself to attention as surplus [Überschuss] which precedes and exceeds every foreign observation [Fremdbetrachtung] and foreign treatment [Fremdbehandlung] of the alien. Not only the reduction of the alien to one's own, but also the attempt of a 
[13] synthesis between the two belongs to the violent acts which silence the demand [Anspruch] of the alien." (Waldenfels, 1999, p. 50; transl. H.S.)

To sum up my brief outline of Waldenfels' phenomenology of the alien, the metaphor of the alien as "sting" [Stachel] is a strong expression of the demand of the alien, its challenge coming from outside, its creation of a pathic situation (Waldenfels, 2011, p. 21-34). "The sting of the alien not only puts in motion, it penetrates into one's own flesh like the sting of a gadfly, the symbol of Socratic questioning" (Waldenfels, 1990, p. 8, transl. H.S.).

\section{Nakamura's Concept of Xenosophia}

There are strong parallels in the argumentation of Waldenfels and Nakamura. Nakamura's building blocks for a theory of the alien clearly rest on the foundation of Waldenfels' phenomenology of the alien. Nevertheless, Nakamura, who puts the discussion under 'xenosophia' as umbrella term, offers valuable contributions to methodological and conceptual precisions. Nakamura is concerned with sharpening the distinction between other and alien. While Nakamura (2000, p. 115), in his critical reading, concludes that Waldenfels only "takes us to the border of otherness and alienness, but does not cross that border," Nakamura intends to sharpen this distinction, in order to profile the alien and state more precisely that the replacement of alienness with otherness is the problem (for which he uses the term 'exotism,' as will be explained shortly). Related to his concern about a clear distinction between other and alien is Nakamura's proposal for introducing a clear distinction between inner/vertical alienness and outer/horizontal alienness.

We need to insist on these sharp distinctions and prevent any confusion, this is Nakamura's thesis, in order to preserve the alienness of the alien. And the alienness of the alien consists of its autonomy, independence, and principal incomprehensibility; the alien comes from the outside and can only be experienced. Thus, the other must not be mistaken for the alien. This implies that we need to be suspicious against any assimilation of the alien, since assimilation implies that the real experience of the alien is substituted by a construction of the alien as other. Nakamura calls the assimilation of the alien "exotism:"

"Exotism ... consists in the application of patterns of interpretation for internal alienness to phenomena of outer alienness, in order to divert or eliminate irritation." (Nakamura, 2000, p. 49 , transl. H.S.)

This is of particular importance for the xenography, the description of types and patterns of how the alien was and is perceived. And exotism has dominated ethnological and inter-cultural perception for centuries - and may indicate the basic mechanism of how prejudice develops. Thus, the perception of the alien, which may allow irritation, is rather the exception. Therefore, we may need to pay attention to the proposal to distinguish other and alien - to be able to resist the problem that the alien is replaced by the other. [14] 
"In exotism, the alien, which is in experience uncontrollable, is - counter to the resistance of factual autonomy - made-other [verandert], is made into an Other. That, which, on a 'virtual' meta-level, is constituted and orchestrated [inszeniert] as supposed alien, suppresses that, which on the horizon level has been experienced as alien. Exotism is thus the replacement of the experienced alien by an orchestrated alien [durch inszeniertes Fremdes], replacement of alienness by otherness." (Nakamura, 2000, p. 72, transl. H.S.)

Xenosophia, in contrast, is described by Nakamura (2000, p. 238) as a process, which originates at the starting point of the experience of the alien - and this is an experience of crisis in which the usual hermeneutical procedures (of development and correction of pre-understanding) come to a stop. This is an experience of a radical contradiction, an experience of being thrown out of the hermeneutical circle. Nakamura speaks of a "non-hermeneutical reservation." The crisis is created by the unexpected, challenging and irritating experience that cannot and must not simply be assimilated or integrated.

The non-hermeneutical reservations are necessary, Nakamura (2000, p. 240) says, to prevent potential misperception and misinterpretation of the alien: "The core of the non-hermeneutic is the memento, which keeps alive the moment of irritation against the coming-to-terms with and re-visions of the irritation." Xenosophia resists the premature abandonment of irritation and perplexity - that is caused by the "sting" of the alien, to recall Waldenfels.

It is adequate and necessary, after the argumentation on a high philosophicalphenomenological level, to descend to the level of a practical xenology. The outlook on a xenology in Nakamura's book (p. 243-260) thus deals with the ethics that may follow from the consideration of xenosophia. It is unavoidable that we engage in the attempt to understand and interpret the alien, the challenge of the alien calls for a response. Understanding the alien requires a responsive habitus, as Waldenfels maintains, which, however, must never ignore (memento!) the sting of the alien. In this process, we should always conserve an awareness of the difference between alienness and otherness. In other words, understanding the alien needs to at least maintain the reservations of the preliminariness of any understanding. There remains incompleteness, uncertainty, and the potential need for revision. The least that we need to preserve is the awareness that any act of understanding is an annexation, an assimilation of the alien to the categories of one's own. And this can never be completely adequate. It is, as Nakamura (p. 249) says, like a sentence in an ongoing language game. Beneath the interpretation of the alien in terms of otherness, there needs to be an ongoing awareness of the alienness of the alien. And this constitutes a clear difference to the approach in which the alien is reduced to an "other" without any reservations and memento.

[15] 


\section{Conceptualizing Xenosophia in Respect to the Hierarchy of Styles of Responding to the Strange - A Conclusion}

Our own conceptualization of xenosophia owes much to the phenomenological reflections of Waldenfels and Nakamura. But in the context of our past research and thus of the results presented in this book, the encounter with the strange has a rather specific focus on inter-cultural and inter-religious relations, on prejudices and their potential salutogenic opposite(s). The question therefore is this: How should we draft the differences in the patterns or styles of responding to strangeness in our multi-cultural and multi-religious societies? Can we justify a hierarchy of styles of responding to strangeness? Is there a plausible developmental model of how to understand - and potentially prescribe - statistical and biographical paths to xenophobia? Thus, we draw conclusions about the contribution of the phenomenological reflection on xenosophia and expand on these reflections to answer these questions.

The preeminent and most important characteristics of 'xenosophia' as used in our research and thus in the research presented in this book can be summarized in the following theses:

1. Xenosophia begins with experiences of resistance and irritation. Strangers provide each other with experiences of strangeness, for which there is no instant way of understanding and coming to terms with.

2. Nevertheless, irritation and resistance call for a reaction. And here we cannot react otherwise than applying our categories of understanding (in Nakamura's terms: apply our categories from coming to terms with inner, vertical experiences of alienness to the outer, horizontal experiences of alienness).

3. The decisive question then is this: whether such understanding is regarded definitive and final, closing the door to any irritation, or whether such understanding is regarded as provisional, as a sentence in a language gamewith at least the memento to non-hermeneutical reservations. Thus, xenosophia includes the rec- ognition and admission that my own understanding is not the absolute truth; Xenosophia is based on preconditions such as tolerance for complexity and on the virtue of humility, hermeneutical humility, intellectual humility. ${ }^{4}$ Even though tolerance of complexity and intellectual humility are necessary precondi- tions, we find Waldenfels' focus on the 'demand' or 'sting' most precise for the question of how we relate to the alien:

4. The "sting of the alien" must not be abandoned and silenced. In Waldenfels' terms, the experience of the alien is a demand that calls for a response. And these responses are creative acts exceeding any pre-given ways of responding. Xenosophia, we may conclude, includes inspiration and creativity in responding to the demand of the alien/the strange. [16]

\footnotetext{
${ }^{4}$ Recently, there is a lively discussion of intellectual humility (see, for example, Davis et al., 2016) and its relation to religious tolerance (Hook et al., 2016). Also scales have been developed for intellectual humility (McElroy et al., 2014; Krumrei-Mancuso \& Rouse, 2016). We welcome this discussion and appreciate its contribution to the exploration of preconditions for xenosophia.
} 
5. Xenosophia demands dialog. The experience of strangeness and the irritation that comes with it is mutual. This process of inter-action should be noted also for the xenosophic style. This justifies that, in the conceptualization of the xeno- sophic schema of the Religious Schema Scale, we have explicitly included "inter-religious dialog," thus the subscale name reads "xenosophia/inter-religious dialog." The xenosophic schema presupposes a symmetric inter-action "at the same eye level."

6. The mutual irritation includes content dimensions regarding worldviews and behavior. The mutual experience of alienness then invites the questioning and potentially revising of one's own worldview and practice. Dialog, inter-cultural and inter-religious dialog, includes such mutual inter-action of experiences of difference and resistance.

7. Regarding the outcome of the "non-hermeneutical reservation," the outcome of keeping alive the irritation (or at least the memento for this irritation), we propose: Xenosophia may lead to wisdom. The term 'xenosophia' includes 'sophia,' 'wisdom.' And our conclusion with reference to Waldenfels is this: Wisdom is the "surplus" of the encounter with the strange. Xenosophia is the wisdom that we may expect to emerge from the irritating encounter with the strange. (Unfortunately, this positive outcome is not discussed in Nakamura's text.)

Now we go one step further and re-consider - in the rearview mirror, as it werethe concepts of xenophobia and tolerance in the light of our definition of xenosophia. Prejudice and xenophobia, we may conclude from the conceptualization of xenosophic habitus, rest on a process by which the strange is assimilated and treated as whatever our more or less prejudiced categories construct as other. We may call this, with Nakamura, "exotism"-with all the potential fatal consequences that may follow from this exotism, if otherness is not curbed by ethical prescriptions, but loaded with aversive downgrading because of anxieties or even pure hate. Thus we may understand xenophobia as ethically un-curbed otherness.

Thus, tolerance can also be, and to a large extent is, based on the mechanism by which the strange is constructed and made the other. But in tolerance, otherness is curbed by ethical prescriptions or legal regulations. Of course, the xenosophic habitus also stimulates and promotes tolerant behavior. But the conception(s) of tolerance do not necessarily require the non-hermeneutical reservation that is supposed to keep the door open for the irritation and the demand of the strange. Thus, we may conclude that tolerance rests on constructions of the strange as other - constructions, which are not debatable and do not allow irritations, but are taken for granted. This sheds new light on Forst's (2013) four conceptions of tolerance: The "permission conception" grants elementary human rights to the other; the "coexistence conception" curbs otherness by the negative version of the Golden Rule; the "respect conception" treats the convictions and practices of others as legally and politically equal; and the "esteem conception" may express high regard to the others' convictions and practices, but does not necessarily require that one's own construction of the other is regarded preliminary. 
[17] Finally, the above reflections allow placing the styles of responding to the strange into a hierarchical order. From the philosophical argumentation in this chapter, it is clear that xenosophia is more adequate than tolerance and much more adequate than xenophobia. The xenosophic habitus responds in the most appropriate way to the needs and the demands of all participants, including the strangers; thus it contributes best to the common good and minimizes violence, misinterpretation and prejudice.

And also the hierarchy of the developmental sequence of religious styles or faith stages receives support from our reflection on xenosophia. I have argued elsewhere (Streib, 2013) that the hierarchical order of the sequence of faith stages or of religious styles needs philosophical-ethical and/or theological grounding. Now here, in the context of the philosophical-hermeneutical conceptualization of xenosophia, the hierarchy of religious styles can be put on a solid philosophical foundation, especially regarding the difference between individuative-reflective faith (Fowler), individuative-systemic religious style (Streib), and the religious schema of "fairness, tolerance and rational choice," on the one hand, and the conjunctive faith (Fowler), the dialogical religious style (Streib), and the corresponding religious schema of "xenosophia/inter-religious dialog," on the other hand.

A more comprehensive picture of xenosophia in the developmental framework including the full range of correspondences between Fowler's stages of faith, religious styles, the religious schemata and styles of inter-religious negotiation, on the one hand, and the xenological patterns as developed in this chapter, on the other hand, will be presented in Chap. 3 (see Table 3.1).

\section{Including Xenosophia in Empirical Research on Prejudice}

In this outlook on the operationalization of xenosophia in empirical research, we focus on our own work and on how xenosophia has been included in the research presented in this book. This outlook is thus a kind of bridge to Chaps. 3 and 4, in which qualitative and quantitative instruments and research designs will be described comprehensively.

We are probably the first to explicitly use 'xenosophia' in empirical research. In the Religious Schema Scale (RSS, Streib et al. 2010), which we have developed, validated and included in most of our completed and current research projects, one of three subscales is supposed to assess xenosophia (and dialog): The RSS subscale xenosophia/inter-religious dialog (xenos). The five items of the subscale read:

\footnotetext{
"We can learn from each other what ultimate truth each religion contains."

"We need to look beyond the denominational and religious differences to find the ultimate reality."

"When I make a decision, I am open to contradicting proposals from diverse sources and philosophical standpoints."
} 
[18] "Religious stories and representations from any religion unite me with the ultimate universe."

"The truth I see in other world views leads me to re-examine my current views."

It is obvious that, in the xenos subscale, xenosophia is assessed in the context of religion. And thereby the openness for inter-religious encounter and dialog is emphasized. But the red thread running through all items is the readiness to leave the shell of one's own religion and world view and the expectation that exposure to the (potentially alien) truth claims and (potentially alien) symbols of other religions and world views may set in motion a dialog - with the expectation that something ultimate may emerge. The xenos items clearly and explicitly address the challenge of difference and contradiction that may lead to the re-examination of one's own truths. Thus, the xenos subscale reflects the essential features of our concept of xenosophia, as detailed above.

Of the three religious schemata that are measured with the RSS (Streib et al. 2010), we expect especially the schema of xenosophia/inter-religious dialog to be clearly opposed to - and potentially a preventive resource against - prejudice and xenophobia. This assumption receives support from previous research with 340 German adolescents (Streib \& Klein, 2014), in which we have used stepwise regression to demonstrate the clearly negative effect of xenos on anti-Islamic prejudice as the dependent variable. Results from our current study (presented in Chap. 6) not only corroborate these findings with considerably higher statistical power, they demonstrate that a key role is played by the schema xenosophia/inter-religious dialog: higher agreement with xenos clearly correlates and predicts higher agreement with Islam as part of the Western world and the appreciation of religious diversity, and higher rejection of xenophobia and Islamophobia. We can conclude with the claim that we have successfully completed at least first steps for including 'xenosophia' in prejudice research.

Besides the operationalization of xenosophia in a quantitative instrument, we attend to xenosophia also in qualitative research using the faith development interview (for details, see Chap. 3). In the framework of faith development theory (Fowler, 1981), xenosophia, as has been mentioned already, corresponds to Fowler's Stage Five of "conjunctive faith" / to the "dialogical religious style" (Streib, 2001), a style of dealing with religious plurality with the appreciation of dialog and mutual learning, which is characterized by an open attitude towards religious difference. In our basic evaluation procedure indications of dialogical and xenosophic structures are identified in the answers to the 25 questions in the interview. But also through content analysis and narrative analysis, we are attentive to indices of xenosophia and to the narration of events (marked by experiences of strangeness causing reactions such as irritation, perplexity or resistance) that may be interpreted as triggers for biographical developments toward xenosophia. This way, our qualitative approach includes the assessment of biographical paths to xenosophia.

Finally, regarding other constructs and measures for our study (see Chap. 4 for a comprehensive presentation), basic assumptions are supported from the concepts that have been developed in this chapter. In short, xenosophia requires tolerance of complexity and openness to change. We have used the following instruments: 
[19] Openness to change vs. conservation belongs to the assessment of values according to Schwartz (2007) and is one of the two coordinates in value space. Tolerance of complexity has been assessed with the 20 -item scale by Radant and Dalbert (2006, 2007). The hypothesis that these constructs are particularly effective in predicting xenosophia is based on the following considerations: Because the xenosophic habi- tus should be able to stand perplexity and irritation and throughout take a non- hermeneutical stance (at least consider the non-hermeneutical reservations as memento), the individual development of such habitus go hand in hand with high openness to change and with high tolerance of complexity. Thus, we hypothesize that high openness to change and high tolerance of complexity strongly corre- late with and predict xenosophia as measured with the RSS subscale xenos.

\section{References}

Adorno, T. W., Frenkel-Brunswik, E., Levinson, D. J., \& Sanford, R. N. (1950). The authoritarian personality (1st ed.). New York: Harper\&Row.

Allport, G. W. (1954). The nature of prejudice (25th anniversary edition ed.). Cambridge: Perseus books 1979.

Allport, G. W. (1966). The religious context of prejudice. Journal for the Scientific Study of Religion, 5, 447-457.

Altemeyer, B. (1996). The authoritarian specter. Cambridge, MA: Harvard University Press.

Altemeyer, B. (2003). Why do religious fundamentalists tend to be prejudiced? The International Journal for the Psychology of Religion, 13, 17-28. https://doi.org/10.1207/ S15327582IJPR1301_03.

Altemeyer, B. (2006). The authoritarians. Winnipeg: University of Manitoba, Department of Psychology.

Altemeyer, B., \& Hunsberger, B. (1992). Authoritarianism, religious fundamentalism, quest and prejudice. The International Journal for the Psychology of Religion, 2, 113-133. https://doi. org/10.1207/s15327582ijpr0202_5.

Altemeyer, B., \& Hunsberger, B. (2004). A revised religious fundamentalism scale: The short and sweet of it. The International Journal for the Psychology of Religion, 14, 47-54.

Altemeyer, B., \& Hunsberger, B. (2005). Fundamentalism and authoritarianism. In R. F. Paloutzian \& C. L. Park (Eds.), Handbook of the psychology of religion and spirituality (pp. 378-393). New York; London: The Guilford Press.

Brandt, M. J., \& Reyna, C. (2010). The role of prejudice and the need for closure in religious fundamentalism. Personality and Social Psychology Bulletin, 36, 715-725.

Brauer, M., \& Er-rafiy, A. (2011). Increasing perceived variability reduces prejudice and discrimination. Journal of Experimental Social Psychology, 47, 871-881.

Davis, D. E., Rice, K., McElroy, S., DeBlaere, C., Choe, E., Van Tongeren, D. R., \& Hook, J. N. (2016). Distinguishing intellectual humility and general humility. Journal of Positive Psychology, 11, 215-224.

Dhont, K., Roets, A., \& Van Hiel, A. (2013). The intergenerational transmission of need for closure underlies the transmission of authoritarianism and anti-immigrant prejudice. Personality and Individual Differences, 54, 779-784.

Doehring, C. (2013). An applied integrative approach to exploring how religion and spirituality contribute to or counteract prejudice and discrimination. In K. I. Pargament, A. Mahoney, \& E. P. Shafranske (Eds.), APA handbooks in psychology: APA handbook of psychology, religion and spirituality: Vol 2 (pp. 389-404). Washington: APA. 
Er-rafiy, A., \& Brauer, M. (2010). Effective reduction of prejudice and discrimination: Methodological considerations and three field experiments. Revue Internationale de Psychologie Sociale, 23, 57-95.

Er-rafiy, A., \& Brauer, M. (2012). Increasing perceived variability reduces prejudice and discrimination: Theory and application. Social and Personality Psychology Compass, 6, 920-935.

Forst, R. (2013). Toleration in conflict: Past and present. Cambridge: Cambridge University Press.

Fowler, J. W. (1981). Stages of faith. The psychology of human development and the quest for meaning. San Francisco: Harper\&Row.

Goclowska, M. A., \& Crisp, R. J. (2013). On counter-stereotypes and creative cognition: When interventions for reducing prejudice can boost divergent thinking. Thinking Skills and Creativity, 8, 72-79.

Hood, R. W., Hill, P. C., \& Spilka, B. (2009). The psychology of religion: An empirical approach (4th ed.). New York: Guilford Press.

Hook, J. N., Farrell, J. E., Johnson, K. A., Van Tongeren, D. R., Davis, D. E., \& Aten, J. D. (2016). Intellectual humility and religious tolerance. Journal of Positive Psychology, 12, $29-35$.

Hunsberger, B., \& Jackson, L. M. (2005). Religion, meaning, and prejudice. Journal of Social Issues, 61, 807-826. https://doi.org/10.1111/j.1540-4560.2005.00433.x.

Hunsberger, B., Owusu, V., \& Duck, R. (1999). Religion and prejudice in Ghana and Canada: Religious fundamentalism, right-wing authoritarianism and attitudes toward homosexuals and women. The International Journal for the Psychology of Religion, 9, 181-194.

Krumrei-Mancuso, E. J., \& Rouse, S. V. (2016). The development and validation of the comprehensive intellectual humility scale. Journal of Personality Assessment, 98, 209-221.

McElroy, S. E., Rice, K. G., Davis, D. E., Hook, J. N., Hill, P. C., Worthington, E. L., \& Van Tongeren, D. R. (2014). Intellectual humility: Scale development and theoretical elaborations in the context of religious leadership. Journal of Psychology and Theology, 42, 19-30.

McFarland, S., Webb, M., \& Brown, D. (2012). All humanity is my ingroup: A measure and studies of identification with all humanity. Journal of Personality and Social Psychology, 103, 830-853.

McFarland, S., Brown, D., \& Webb, M. (2013). Identification with all humanity as a moral concept and psychological construct. Current Directions in Psychological Science, 22, 194-198.

Nakamura, Y. (2000). Xenosophie: Bausteine für eine Theorie der Fremdheit [Xenosophia. Building blocks for a theory of the alien]. Darmstadt: Wissenschaftliche Buchgesellschaft.

Paluck, E. L. (2016). How to overcome prejudice. Science, 352, 147.

Paluck, E. L., \& Green, D. P. (2009). Prejudice reduction: What works? A review and assessment of research and practice. Annual Review of Psychology, 60, 339-367.

Radant, M., \& Dalbert, C. (2006). Dimensionen der Komplexitätstoleranz: Ergebnisse einer Synopse von Persönlichkeitskonstrukten [Dimensions of tolereance of complexity: Results of a synopsis of personality constructs], Paper for the 45. Nürnberg: Kongress der Deutschen Gesellschaft für Psychologie.

Radant, M., \& Dalbert, C. (2007). The dimensions of the complexity tolerance: A synopsis of personality constructs. Paper for the 10th European congress of psychology, Prague.

Reysen, S., \& Hackett, J. (2015). Further examination of the factor structure and validity of the identification with all humanity scale. Current Psychology, 1-9.

Schäfer, H. (2015). Identität als Netzwerk. Habitus, Sozialstruktur und religiöse Mobilisierung. Wiesbaden: Springer VS.

Schwartz, S. H. (1992). Universals in the content and structure of values: Theoretical advances and empirical tests in 20 countries. In M. P. Zanna (Ed.), Advances in experimental social psychology (pp. 1-65). Orlando: Academic Press.

Schwartz, S. H. (2003). A proposal for measuring value orientations across nations. In Questionnaire development report of the European social survey (pp. 259-319). Online at: http://www.europeansocialsurvey.org/docs/methodology/core_ess_questionnaire/ESS_core_ questionnaire_human_values.pdf. Accessed $23 \mathrm{Feb} 2018$. 
Schwartz, S. H. (2007). A theory of cultural value orientations: Explication and applications. In Y. Esmer \& T. Pettersson (Eds.), Measuring and mapping cultures: 25 years of comparative value surveys (pp. 33-78). Leiden: Brill Publishers.

Streib, H. (2001). Faith development theory revisited: The religious styles perspective. The International Journal for the Psychology of Religion, 11, 143-158. https://doi.org/10.1207/ S15327582IJPR1103_02.

Streib, H. (2013). Conceptualisation et mesure du développement religieux en termes de schémas et de styles religieux - Résultats et nouvelles considérations. In P.-Y. Brandt \& J. M. Day (Eds.), Psychologie du développement religieux: questions classiques et perspectives contemporaines (pp. 39-76). Geneva: Labor et Fides.

Streib, H., \& Klein, C. (2014). Religious styles predict inter-religious prejudice: A study of German adolescents with the religious schema scale. The International Journal for the Psychology of Religion, 24, 151-163. https://doi.org/10.1080/10508619.2013.808869.

Streib, H., Hood, R. W., Keller, B., Csöff, R.-M., \& Silver, C. (2009). Deconversion. qualitative and quantitative results from cross-cultural research in Germany and the United States of America. Göttingen: Vandenhoeck \& Ruprecht.

Streib, H., Hood, R. W., \& Klein, C. (2010). The religious schema scale: Construction and initial validation of a quantitative measure for religious styles. The International Journal for the Psychology of Religion, 20, 151-172. https://doi.org/10.1080/10508619.2010.481223.

Tadmor, C. T., Hong, Y., Chao, M. M., Wiruchnipawan, F., \& Wang, W. (2012). Multicultural experiences reduce intergroup bias through epistemic unfreezing. Journal of Personality and Social Psychology, 103, 750-772.

Todd, A. R., \& Burgmer, P. (2013). Perspective taking and automatic intergroup evaluation change: Testing an associative self-anchoring account. Journal of Personality and Social Psychology, 104, 786-802.

Van Hiel, A., Pandelaere, M., \& Duriez, B. (2004). The impact of need for closure on conservative beliefs and racism: Differential mediation by authoritarian submission and authoritarian dominance. Personality and Social Psychology Bulletin, 30, 824-837.

Waldenfels, B. (1990). Der Stachel des Fremden [The Sting of the Alien]. Frankfurt/M: Suhrkamp.

Waldenfels, B. (1997a). Phänomenologie des Eigenen und des Fremden [phenomenology of the own and the alien]. In H. Münkler (Ed.), Furcht und Faszination. Facetten der Fremdheit (pp. 65-83). Berlin: Akad.-Verlag.

Waldenfels, B. (1997b). Topographie des Fremden [Topography of the Alien]. Frankfurt/M: Suhrkamp.

Waldenfels, B. (1999). Der Anspruch des Fremden [The demand of the alien]. In R. Breuninger (Ed.), Andersheit - Fremdheit - Toleranz (pp. 31-51). Ulm: Humboldt-Studienzentrum.

Waldenfels, B. (2003). From intentionality to responsivity. In R. Bernet \& D. J. Martino (Eds.), Phenomenology today: The Schuwer Spep lectures, 1998-2002 (pp. 23-35). Pitsburg: Duqesne University.

Waldenfels, B. (2007). The question of the other. The Tang Chun-I lecture for 2004. Albany; Hong Kong: SUNY Press; The Chinese University Press.

Waldenfels, B. (2011). Phenomenology of the alien: Basic concepts [Grundmotive einer Phänomenologie des Fremden, Frankfurt/M.: Suhrkamp, 2006, transl. By a. Kozin and T. Stähler]. Evanston: Northwestern University Press. 